\title{
LETTER
}

\section{Hydroxyethyl starch 130/0.4 or hypertonic saline solution to decrease inflammatory response in hemorrhagic shock?}

\author{
Pierre Esnault", Bertrand Prunet, Jean Cotte, Pierre-Julien Cungi, Audrey Alonso and Ambroise Montcriol
}

See related research by Chen et al., http://ccforum.com/content/17/4/R141

We read with great interest the study by Chen and colleagues highlighting interest in hydroxyethyl starch (HES) 130/0.4 in treatment after hemorrhagic shock to ameliorate oxidative stress and the inflammatory response in a rat model. Compared with HES 200/0.5 and succinylated gelatin, the authors showed that infusions of HES 130/0.4 significantly reduced malondialdehyde levels and myeloperoxidase activity and also inhibited about $50 \%$ of TNF- $\alpha$ production in the intestine [1].

However, we regret the lack of assessment of another resuscitative fluid: the hypertonic saline solution (HTS). In our level 1 trauma center, we chose to use HTS because we have some concerns about HES safety. Indeed, HES may induce coagulopathy and increase risk of renal-replacement therapy [2]. HTS has several advantages due to its osmotic effects. Firstly, it leads to restoration of circulating volume with a smaller volume of fluid. Secondly, it reduces intracranial pressure in case of associated traumatic brain injury [3]. In addition, HTS attenuates the increase in plasma concentration of IL- $1 \beta$, IL-6, IFN- $\gamma$ and TNF- $\alpha$, suggesting that HTS may also limit the inflammatory response to hemorrhage and reperfusion [4]. One of its inconveniences may be the increased risk of acute kidney injury due to hyperchloremic metabolic acidosis decreasing renal blood flow; however, this effect was especially demonstrated when using large amounts of $0.9 \%$ saline solution [5].

We suggest that, in 2013, studies on fluid resuscitation should compare all the available resuscitative fluids, and not just HES, currently under concern for safety reasons.
Abbreviations

HES: hydroxyethyl starch; HTS: hypertonic saline solution; IFN: interferon; IL: interleukin; TNF: tumor necrosis factor.

\section{Competing interests}

The authors declare that they have no competing interests.

Published: 04 Oct 2013

\section{References}

1. Chen G, You G, Wang Y, Lu M, Cheng W, Yang J, Zhao L, Zhou H: Effects of synthetic colloids on oxidative stress and inflammatory response in hemorrhagic shock: comparison of hydroxyethyl starch 130/0.4, hydroxyethyl starch 200/0.5, and succinylated gelatin. Crit Care 2013, 17: R141.

2. Perner A, Haase N, Guttormsen AB, Tenhunen J, Klemenzson G, Åneman A, Madsen KR, Møller MH, Elkjær JM, Poulsen LM, Bendtsen A, Winding R, Steensen M, Berezowicz P, Søe-Jensen P, Bestle M, Strand K, Wiis J, White JO, Thornberg KJ, Quist L, Nielsen J, Andersen LH, Holst LB, Thormar K, Kjældgaard AL, Fabritius ML, Mondrup F, Pott FC, Møller TP, et al: Hydroxyethyl starch 130/0.42 versus Ringer's acetate in severe sepsis. N Engl J Med 2012, 367:124-134.

3. Marko N: Hypertonic saline, not mannitol, should be considered goldstandard medical therapy for intracranial hypertension. Crit Care 2012, 16:113.

4. Bahrami S, Zimmermann K, Szelényi Z, Hamar J, Scheiflinger F, Redl H, Junger WG: Small-volume fluid resuscitation with hypertonic saline prevents inflammation but not mortality in a rat model of hemorrhagic shock. Shock 2006, 25:283-289.

5. Yunos NM, Bellomo R, Hegarty C, Story D, Ho L, Bailey M: Association between a chloride-liberal vs chloride-restrictive intravenous fluid administration strategy and kidney injury in critically ill adults. JAMA 2012, 308:1566-1572.

$10.1186 / \mathrm{cc} 13043$

Cite this article as: Esnault et al:: Hydroxyethyl starch 130/0.4 or hypertonic saline solution to decrease inflammatory response in hemorrhagic shock?. Critical Care 2013, 17:457

\footnotetext{
* Correspondence: pierre.esnault@gmail.com

Department of Intensive Care and Anesthesiology, Sainte Anne Military

Teaching Hospital, Boulevard de Sainte Anne, 83000, Toulon, France
} 